\title{
Selection of Probiotic Microorganisms Against Pathogens of Agricultural Animals
}

\author{
${ }^{1}$ Sagidoldina Zhanar, ${ }^{2}$ Sadanov Amankeldi, ${ }^{2}$ Ratnikova Irina, \\ ${ }^{1}$ Kuandykova Elnara and ${ }^{1}$ Tokkozhaeva Meruert \\ ${ }^{1}$ Kazakh National Agrarian University, Pr. Abai. 8, 050010, Almaty, Kazakhstan \\ ${ }^{2}$ LCC "Research and Production Center for Microbiology and Virology" Bogenbai Batyr str. 105, \\ 050010, Almaty, Kazakhstan
}

Article history

Received: 01-07-2021

Revised: 11-10-2021

Accepted: 21-10-2021

Corresponding Author:

Zhanar Sagidoldina

Biology, Kazakh National

Agrarian University,

Kazakhstan

Email: zhanar.sagidoldina@bk.ru

\begin{abstract}
The work was carried out on the selection of probiotic microorganisms to create an environmentally friendly therapeutic and preventive biological product that is active against pathogens of agricultural animals. According to the results of research, 3 strains of lactic acid bacteria were selected for the construction of a probiotic Lactobacillus plantarum 1, Streptococcus salivarius $20 \mathrm{n}$, Lactobacillus fermentum 15 showed the highest antagonistic activity against test cultures Salmonella typhimurium, Salmonella enteritidis, Salmonella gallinarum, Shigella flexneri 11, Shigella sonnei, Proteus vulgaris, Citrobacter sp., Edwardsiella sp., Yersinia sp., Escherichia coli and the ability to biosynthesize b vitamins (nicotinic acid, Inositol, cyanocobalamin), as well as the Propionibacterim shermanii strain, which showed antagonistic activity against 4 test cultures, namely, Salmonella typhimurium, Salmonella enteritidis, Salmonella gallinarum and Escherichia coli, which is a producer of vitamins nicotinic acid, Inositol and cyanocobalamin.
\end{abstract}

Keywords: Lactic Acid Bacteria, Probiotics, B Vitamins, Antimicrobial Activity

\section{Introduction}

Today, infections remain one of the most important causes of mass human and animal diseases. According to the World Bank, the leading human diseases are diarrhea; intestinal, helminthiasis and tuberculosis up to $84 \%$ of some forms of cancer are etiologically associated with viruses, bacteria and parasites. This gives reason to change the strategy and tactics of preventive measures (Shevchenko, 2002).

In Kazakhstan, one of the most common diseases of humans and animals is also intestinal, caused by pathogens such as Colibacteria, Salmonella and under certain conditions, Enterobacter, Citrobacter, Klebsiella, Protea, Edwardsiella, yeast- like fungi. There is an increase in tuberculosis and brucellosis, frequent cases of purulent focal lesions of various tissues and organs of humans and animals, as well as a variety of inflammatory and septic processes.

The widespread use of antibiotics and chemical growth promoters when fattening farm animals leads to the rapid selection of antibiotic-resistant forms of bacteria in the pet population, to the emergence of dysbiosis, as well as the accumulation of residual substances in meat and other animal products. This makes it necessary to find new approaches to solving this problem. Stricter requirements for the environmental safety of livestock products have forced the world to review many methodological approaches to optimizing control over the epizootic process of diseases caused by opportunistic micro flora and recognize the need to develop a new generation of environmentally safe drugs that can provide biological protection of farm animals and poultry. Probiotic feed additives and preparations containing live bacteria from among the main representatives of the normal intestinal microbiocenosis of animals and poultry, such as lactobacilli, bifidobacteria, enterococci, can meet these requirements most fully (Glushanova et al., 2002; Anadyn and Martunez-Larranaga, 2002).

One of the ways to fight infectious diseases can be the use of probiotics based on lactic acid bacteria for therapeutic and preventive purposes. These microorganisms are symbionts of the gastrointestinal tract, harmless to humans and animals. They have a therapeutic effect due to antimicrobial activity, activation 
of the immune system, mainly a non-specific part of the immune system and normalization of the intestinal microflora. The use of probiotics also helps to improve digestion and increase the productivity of animals. Mechanisms of positive effect on animals of probiotics based on microorganisms suggest.

Inhibition of the growth of potentially harmful microorganisms as a result of the production of antimicrobial substances; competition with them for adhesion receptors and nutrients; activation of immunecompetent cells and stimulation of immunity.

Stimulation of the growth of representatives of the indigenous flora as a result of the production of vitamins and other growth - stimulating factors; normalization of $\mathrm{pH}$; neutralization of toxins.

Restoration and optimization of the functioning of the biofilm lining the digestive tract mucosa.

Changes in microbial metabolism, leading to an increase or decrease in the synthesis and activity of bacterial enzymes and, as a consequence, the production of corresponding metabolites (for example, LDL, glutamine, arginine, vitamins, peptidoglycans, etc.) that have the ability to locally or after penetration into the blood and other biological fluids of the macroorganism directly interfere with the metabolic activity of cells of the corresponding organs and tissues, modulate its morpho-kinetic characteristics, physiological functions, biochemical and behavioral reactions. Other mechanisms: Direct effects of components of microbial cells or their metabolites after their absorption from the digestive tract on enzymatic and other cellular reactions of hormonal, nervous, excretory, immune and other organs and tissues (Gavrilova and Ratnikova 2011; Gavrilova et al., 2011.

The health and productivity of animals depends not only on feeding on diets with sufficient amounts of protein, fat, carbohydrates and minerals, but also on the availability of high-quality vitamin feeds for animals. The importance of vitamins for the animal body is huge. If there is a lack of vitamins in animal diets, the formation of enzymes is disrupted and consequently, the flow and regulation of biosynthesis, as well as specific cell functions are disrupted, which leads to a decrease in animal productivity (Bobrovskaya et al., 2013). Full-fledged vitamin nutrition of animals contributes to the growth of young animals, improve reproductive function and increase milk production in lactating animals, reduce feed costs for the production of $1 \mathrm{~kg}$ of milk and weight gain, improve product quality, prevent animal diseases and others. The Role of $b$ vitamins is great. It also participates in the metabolism of all cells in the body, in the synthesis of DNA and in the assimilation of fats and proteins. Of all the vitamins, B12 has the most complex composition. It cannot be synthesized by plants, animals, or fungi, but only by bacteria. The main biological function of vitamin B8 is its role as a lipotropic factor. It is a part of a number of enzymes, participates in the regulation of cholesterol levels and helps prevent obesity and atherosclerosis. (Blackburn, 2006). In animals with a lack of Inositol, triacylglycerines accumulate and the content of phospholipids in the liver decreases, as a result, fatty liver dystrophy develops. Inositol activates the brain and peripheral nervous system, improves attention and memory and improves mental performance. It also has a calming effect. Vitamin B5 is important for the absorption of proteins, fats and carbohydrates. Vitamin B9 is necessary for the growth and division of all cells, for the transmission of hereditary traits, for the assimilation of proteins, for the synthesis of neurotransmitters and hormones, for the formation of red blood cells. A large amount of folic acid is required for the development of the fetal skeleton and brain (Lim and Im, 2009).

Fat-soluble vitamins are the most fully studied in animal husbandry and veterinary medicine, but the complex of water-soluble $b$ vitamins is still not given enough attention. There is a strong opinion that the presence of a multi-chamber stomach in ruminants populated by microorganisms creates conditions for the synthesis of b vitamins. Therefore, ruminants do not need exogenous intake of these vitamins. However, normal vitamin synthesis can only occur in healthy animals with proper nutrition. Group B hypovitaminoses are observed mainly in young animals, as well as in sick and ill animals (violation of fermentation processes, lack of chewing gum and flatulence of the rumen), pregnant and lactating individuals, dairy cows and patients with subclinical ketosis. (Blackburn, 2006). Research scientists have shown that up to a certain age, young animals are not able to meet their needs for $b$ vitamins by scar synthesis (references). The formation of scar digestion in calves occurs by the age of 6 months. Therefore, it is advisable to give calves of dairy age, raised on limited norms of whole milk and yogurt, b vitamins.

$\mathrm{B}$ vitamins are almost not stored in the reserve, so their lack in the diet or the increased need for conditions of overload of the body (transportation, stages, etc.) quickly causes the phenomenon of hypovitaminosis. Microorganisms that inhabit the gastrointestinal tract are able to synthesize $b$ vitamins, but their performance depends primarily on the state of the host organism. Diseases, especially gastrointestinal diseases, inhibit the activity of beneficial microflora (Kos et al., 2003).

One of the criteria for including microorganisms in probiotics is the ability to produce biologically active substances, including the ability to synthesize vitamins. 
Microorganisms-symbionts of the digestive tract synthesize $\mathrm{b}$ vitamins, namely thiamine $\left(\mathrm{B}_{1}\right)$, Riboflavin $\left(\mathrm{B}_{2}\right)$, pyridoxine $\left(\mathrm{B}_{6}\right)$, cyanocobalamin $\left(\mathrm{B}_{12}\right)$; nicotine $(\mathrm{PP})$, Biotin $\left(\mathrm{B}_{7}\right)$, Pantothenic $\left(\mathrm{B}_{5}\right)$, folic acid $\left(\mathrm{B}_{9}\right)$, which are used by animals after the destruction of microbial cells (Levakhin, 2013).

\section{Purpose of Research}

The aim of the study is to select the most active strains of lactic acid bacteria according to their antimicrobial activity and the ability to synthesize B vitamins for the possibility of using them in probiotics.

The objects of the study were 13 strains of lactic acid bacteria: L. plantarum 1, L. brevis-B-3, L. cellobiosus 58n, S. lactis 43n, S. lactis 33n, L. casei $173 \mathrm{a}$, L. casei 7, L. plantarum 1n, L. fermentum 50n, L. acidophilus $11, \mathrm{~S}$. salivarius $20 \mathrm{~h}, \mathrm{~S}$. lactis $48 \mathrm{n}, \mathrm{S}$. salivarius 39n, L. fermentum 15, isolated from the gastrointestinal tract of healthy animals (calves)and a strain of propionic acid bacteria Propionibacterim shermanii 34 (Kozlov, 1998; West-Eberhard 2003; Wagner et al., 2014).

The antimicrobial activity of lactobacilli and propionic acid bacteria was determined by diffusion in agar. The number of viable cells of lactic acid and propionic acid bacteria was $5 \times 108 \mathrm{CFU} / \mathrm{mL}$. The number of cells in the test cultures was 1 billion and $0.1 \mathrm{~mL}$ was added to each Petri dish (Kumar et al., 2012).

The following test cultures were used: Salmonella typhimurium, Salmonella enteritidis, Salmonella gallinarum, Shigella flexneri, Shigella sonnei, Proteus vulgaris, Citrobacter sp., Edwardsiella sp., Yersinia sp., Escherichia coli.

Lactic acid and propionic acid bacteria were grown on the MRS nutrient medium ( $\mathrm{g} / \mathrm{l})$ : yeast extract-5.0; meat extract - 10.0; pepton-10.0; glucose-20.0; ammonium citric acid -2.0; sodium acetic acid -5.0; twin-80 - 1,0; $\mathrm{KH}_{2} \mathrm{PO}_{4}-2,0 ; \mathrm{MgSO}_{4} \cdot 7 \mathrm{H}_{2} \mathrm{O}-0,2 ; \mathrm{MnSO}_{4} \cdot 4 \mathrm{H}_{2} \mathrm{O}-0,05 ;$ $\mathrm{CoCl}_{2}$ - 0,01; $\left(\mathrm{NH}_{4}\right)_{2} \mathrm{SO}_{4}$ - 1,0. Vitamin-forming capacity was determined by photometric method on the SPECORD "UV VIS" spectrophotometer.

Standard methods for finding average values and their average errors were used for mathematical processing of the results (Valentine et al., 1987)

\section{Research Results}

The antagonistic activity of lactic acid and propionic acid bacteria strains against pathogenic strains of microorganisms was determined for inclusion in the composition of a therapeutic and prophylactic drug for the treatment of diseases of farm animals.
Data from studies to determine antagonistic activity are presented in the Table 1.

As can be seen from the presented table number 1, it was found that of the 14 tested strains of lactic acid and propionic acid bacteria, all showed some degree of antagonistic activity against the test cultures taken in the experiment. The studied bacterial strains showed the least antimicrobial activity in relation to 3 test cultures, namely - Shigella flexneri 11, Shigella sonnei and Proteus vulgaris. Eight strains of bacteria were not active in the test cultures listed above (Kozlov, 2008; Arendt et al., 2016).

It was revealed as a result of our experiment that three strains of lactic acid bacteria have the widest spectrum of antimicrobial activity - L. plantarum, S. salivarius 20n, L. fermentum 15 .

They showed activity to all test cultures taken in the experiment: Salmonella typhimurium, Salmonella enteritidis, Salmonella gallinarum, Shigella flexneri, Shigella sonnei, Proteus vulgaris, Citrobacter sp., Edwardsiella sp., Yersinia sp., Escherichia coli. The zone of growth inhibition ranged from 8 to $20 \mathrm{~mm}$. To Salmonella typhimurium the most active strains were L. plantarum 1, L. fermentum 15.

Bacterial cultures taken in the study (L. plantarum 1, L. brevis-B-3, L. cellobiosus 58n, S. lactis 43n, S. lactis 33n, L. casei 173a, L. casei 7, L. plantarum 1n, L. fermentum 50 n, L. acidophilus 11, S. salivarius 20n, S. lactis 48 n, S. salivarius 39n, L. fermentum 15, Propionibacterim shermanii 34.), were also studied for the ability to biosynthesize vitamins B5, B8, B12 ... The research results are presented in Table 2 . (Bondarenko et al., 2003)

Table 2 - biosynthesis of vitamin $\mathrm{B}_{5}$ (nicotinic acid), $\mathrm{B}_{8}$ (Inositol), $\mathrm{B}_{12}$ (cyanocobalamin) by cultures of lactic and propionic acid bacteria

All strains of lactic acid and propionic acid bacteria, taken in the experiment, synthesize vitamin B8 (inositol). P. shermanii $34(1.0 \mathrm{U} / \mathrm{mg})$ showed the highest activity of inositol biosynthesis. Three bacterial strains - L. plantarum 1, S. salivarius 20n, L. fermentum 15, P. shermanii 34 synthesized this vitamin at a high level in comparison with other microorganisms taken in the experiment.

Only 5 strains of 14 bacterial strains were capable of biosynthesis of vitamin B5 (nicotinic acid), namely L. plantarum 1, L. casei 7, S. salivarius 20 n, L. fermentum 15, P. shermanii 34.

The greatest ability to biosynthesize vitamin $B_{12}$ (cyanocobalamin) was shown by a strain of propionic acid bacteria. shermanii 34 (2.78 units/mg). Three strains of lactic acid bacteria - L. plantarum 1, S. salivarius 20n, L. fermentum 15 cyanocobalamin is produced in an amount from 0.18 to $0.51 \mathrm{u} / \mathrm{mg}$ (Egorov, 1994; Urbakh, 1975). 
Table 1: Determination of antimicrobial activity of lactic and propionic acid bacteria

\begin{tabular}{|c|c|c|c|c|c|c|c|c|c|c|}
\hline \multirow[b]{2}{*}{ Strain of bacteria } & \multicolumn{10}{|c|}{ The diameter of zones of growth inhibition of test cultures, $\mathrm{mm}$} \\
\hline & $\begin{array}{l}\text { Salmonella } \\
\text { Typhimurium }\end{array}$ & $\begin{array}{l}\text { Salmonella } \\
\text { Enteritidis }\end{array}$ & $\begin{array}{l}\text { Salmonella } \\
\text { Gallinarum }\end{array}$ & $\begin{array}{l}\text { Shigella } \\
\text { Flexneri } 11 \\
\end{array}$ & $\begin{array}{l}\text { Shigella } \\
\text { Sonnei }\end{array}$ & $\begin{array}{l}\text { Proteus } \\
\text { Vulgaris }\end{array}$ & $\begin{array}{l}\text { Citrobacter } \\
\text { sp. }\end{array}$ & $\begin{array}{l}\text { Edwardsiella } \\
\text { sp. }\end{array}$ & $\begin{array}{l}\text { Yersinia } \\
\text { sp. }\end{array}$ & $\begin{array}{l}\text { Escherichia } \\
\text { coli }\end{array}$ \\
\hline L. plantarum 1 & $19,0 \pm 0,57$ & $17,0 \pm 0,60$ & $18,0 \pm 0,60$ & $10,0 \pm 0,6$ & $8,0 \pm 0,60$ & $8,0 \pm 0,60$ & $16,0 \pm 1,88$ & $14,0 \pm 0,88$ & $16,0 \pm 1,45$ & $18,0 \pm 1,98$ \\
\hline L. cellobiosus $58 \mathrm{H}$ & $13,0 \pm 0,33$ & $11,0 \pm 1,33$ & $10,0 \pm 1,88$ & 0 & 0 & 0 & $10,0 \pm 0,0$ & $13,0 \pm 0,33$ & $11,0 \pm 0,3$ & $11,0 \pm 0,88$ \\
\hline S. lactis $43 n$ & $14,0 \pm 0,88$ & $11,0 \pm 0,88$ & $15,0 \pm 0,33$ & 0 & $9 \square 0,60$ & 0 & $14,0 \pm 0,55$ & $10,0 \pm 0,33$ & $14,0 \pm 0,98$ & $16,0 \pm 0,32$ \\
\hline S. lactis $33 n$ & $11,0 \pm 0,88$ & $13,0 \pm 0,33$ & $11,0 \pm 1,50$ & 0 & 0 & 0 & $11,0 \pm 0,00$ & $11,0 \pm 1,50$ & $11,0 \pm 0,00$ & $13,0 \pm 1,00$ \\
\hline L. casei $173 a$ & $14,0 \pm 0,33$ & $15,0 \pm 0,94$ & $15,0 \pm 0,33$ & 0 & 0 & 0 & $11,0 \pm 0,0$ & $12,0 \pm 1,50$ & $14,0 \pm 0,33$ & $14,0 \pm 0,33$ \\
\hline L. casei 7 & $14,0 \pm 0,33$ & $14,0 \pm 1,40$ & $13,0 \pm 0,50$ & $9,0 \pm 0,0$ & 0 & 0 & $12,0 \pm 1,50$ & $12,0 \pm 1,57$ & $15,0 \pm 1,50$ & $13,0 \pm 1,00$ \\
\hline L. plantarum $1 \mathrm{~h}$ & $13,0 \pm 0,33$ & $14,0 \pm 0,88$ & $12,0 \pm 1,66$ & 0 & 0 & $8,0 \pm 0,60$ & $11,0 \pm 0,57$ & $11,0 \pm 0,00$ & $13,0 \pm 0,33$ & $13,0 \pm 0,33$ \\
\hline L. fermentum $50 \mathrm{~h}$ & $11,0 \pm 1,33$ & $13,0 \pm 1,00$ & $14,0 \pm 1,50$ & 0 & 0 & 0 & $11,0 \pm 0,0$ & $11,0 \pm 0,57$ & $11,0 \pm 0,33$ & $12,0 \pm 1,66$ \\
\hline L. acidophilus 11 & $11,0 \pm 0,88$ & $14,0 \pm 0,33$ & $11,0 \pm 0,57$ & 0 & 0 & 0 & $12,0 \pm 1,66$ & $10,0 \pm 0,33$ & $14,0 \pm 0,55$ & $11,0 \pm 0,57$ \\
\hline S. salivarius $20 n$ & $14,0 \pm 1,40$ & $16,0 \pm 0,0$ & $10,0 \pm 0,30$ & $13,0 \pm 0,5$ & $9,0 \pm 0,60$ & $9,0 \pm 0,60$ & $18,0 \pm 2,07$ & $18,0 \pm 0,66$ & $17,0 \pm 0,57$ & $15,0 \pm 0,94$ \\
\hline S. lactis $48 h$ & $10 \pm 0,60$ & $13,0 \pm 1,00$ & $12,0 \pm 1,50$ & 0 & 0 & 0 & $17,0 \pm 0,32$ & $13,5 \pm 0,33$ & $12,0 \pm 1,57$ & $13,0 \pm 1,00$ \\
\hline S.salivarius $39 n$ & $15,0 \pm 1,57$ & $11,0 \pm 0,57$ & $13,0 \pm 1,00$ & 0 & 0 & 0 & $10,0 \pm 0,0$ & $10,0 \pm 0,33$ & $14,0 \pm 0,57$ & $12,0 \pm 1,66$ \\
\hline L. fermentum 15 & $16,0 \pm 0,0$ & $20,0 \pm 1,1$ & $15,0 \pm 0,5$ & $10,0 \pm 0,6$ & $11,0 \pm 0,88$ & $11,0 \pm 1,50$ & $18,0 \pm 0,46$ & $14,0 \pm 0,88$ & $18,0 \pm 0,57$ & $19 \pm 0,80$ \\
\hline P. shermanii 34 & $10 \pm 0,0$ & $11,0 \pm 0,88$ & $10,0 \pm 0,33$ & 0 & 0 & 0 & 0 & 0 & 0 & $11 \pm 0,3$ \\
\hline
\end{tabular}

Table 2: Biosynthesis of vitamin $\mathrm{B}_{5}$ (nicotinic acid), $\mathrm{B}_{8}$ (Inositol), $\mathrm{B}_{12}$ (cyanocobalamin) by cultures of lactic and propionic acid bacteria

\begin{tabular}{llll}
\hline & \multicolumn{2}{l}{ Vitamin content, units/mg } \\
& ------------------- & $\mathrm{B}_{12}$ \\
Strain of bacteria & $\mathrm{B}_{5}$ & $\mathrm{~B}_{8}$ & 0,51 \\
\hline L. plantarum 1 & 0,50 & 0,85 & 0 \\
L. cellobiosus 58n & 0 & 0,20 & 0 \\
S. lactis 43n & 0 & 0,34 & 0 \\
S. lactis 33n & 0 & 0,40 & 0 \\
L. casei 173a & 0 & 0,30 & 0,05 \\
L. casei 7 & 0,02 & 0,35 & 0 \\
L. plantarum 1n & 0 & 0,25 & 0,08 \\
L. fermentum 50n & 0 & 0,28 & 0,18 \\
L. acidophilus 11 & 0 & 0,31 & 0 \\
S. salivarius 20n & 0,43 & 0,50 & 0 \\
S. lactis 48H & 0 & 0,29 & 0,25 \\
S. salivarius 39n & 0 & 0,20 & 2,78 \\
L. fermentum 15 & 0,59 & 0,72 & \\
P. shermanii 34 & 2,25 & 1,0 &
\end{tabular}

\section{Conclusion}

Thus, based on the results obtained, three strains of lactic acid bacteria were selected for constructing the probiotic - Lactobacillus plantarum 1, Streptococcus salivarius $20 \mathrm{n}$, Lactobacillus fermentum 15, which showed the highest antagonistic activity in relation to the test cultures taken in the experiment and the ability to biosynthesize B vitamins. (nicotinic acid, inositol, cyanocobalamin).

The Propionibacterim shermanii 34 strain showed antagonistic activity against 4 test cultures, namely Salmonella typhimurium, Salmonella enteritidis, Salmonella gallinarum and Escherichia coli. In addition, propionic acid bacteria synthesize the vitamin cyanocobalamin in a sufficiently large amount compared to other bacteria taken in the study, so it can be used as a part of a probiotic as a producer of this vitamin.

\section{Author's Contributions}

Sagidoldina Zhanar: Make considerable contributions to conception and design.

Sadanov Amankeldi: Reviewing it critically for significant intellectuall content.

Ratnikova Irina: Acquisition of data.

Kuandykova Elnara and Tokkozhaeva Meruert: Analysis and interpretation of data.

\section{Ethics}

This article is original and contains unpublished material. The corresponding author confirms that all of the other authors have read and approved the manuscript and no ethical issues involved.

\section{References}

Anadyn, A., \& Marthnez-Larranaga, M. R. (2006). Pharmacology. 2006. V.12. P. 91-95.

Arendt, D., Musser, J. M., Baker, C. V., Bergman, A., Cepko, C., Erwin, D. H., ... \& Wagner, G. P. (2016). The origin and evolution of cell types. Nature Reviews Genetics, 17(12), 744-757. https://www.nature.com/articles/nrg.2016.127

Blackburn, D. G. (2006). Mammal. Rev. 1991. V. 21. P. 81-96.31. Vorbach C., Capecchi M.R., Penninger J.M. // BioEssays. 2006. V. 28. P. 606-616.

Bobrovskaya, I. V., Neminuschaya, L. A., Eremets, N. K., Provotorova, O. V., Likhasherstova, S. V., Eremets, V. I., \& Samuilenko, A. Y. (2013). Biotechnologies of new probiotics and synbiotic complexes for farm animals and poultry // Biotechnology: reality and prospects in agriculture: materials. International scientific conference, Saratov, 2013.pp. 8-10.

Bondarenko, V. M., Chuprinina, R. P., \& Vorobieva, M. A. (2003). The mechanism of action of probiotic drugs // Biopreparations. - 2003. - No. 3. - S. 2-5. 
Egorov, N. S. (1994). Fundamentals of the doctrine of antibiotics. M.: Publishing house of Moscow State University, 1994.-- 512s.

Gavrilova, N. N., \& Ratnikova, I. A. (2011). Test of therapeutic and preventive effectiveness of probiotic//Abstr. of International Conference «Probiotics and Prebiotics». Koshica, Slavenia, 2011. P. 87.

Gavrilova, N. N., Ratnikova, I. A., \& Melnikov, V. G. (2011). Probiotic Lactovit-K for fighting against coccidiosis infectous-invasive diseases of poultry and diseases of honey bees. Abstr. of HKHKHIV of the Society for Microbial Ecology and DiseaseYokohama, Japan, 33.

Glushanova, N. A., Blinov, A. I., Bakhaev, V. V. (2002). Epidemiology and Infectious Diseases. 2004. No. 6. P.37-39.

Kos, B. V. Z. E., Šušković, J., Vuković, S., Šimpraga, M., Frece, J., \& Matošić, S. (2003). Adhesion and aggregation ability of probiotic strain Lactobacillus acidophilus M92. Journal of applied microbiology, 94(6), 981-987. doi.org/10.1046/j.1365-2672.2003. 01915.x

Kozlov, A. P. (1998) // J. Theor. Biol. 1979. V. 81. P. 117.20. Kirschner M., Gerhart J. // Proc. Natl. Acad. Sci. USA. 1998. V. 95. P. 8420-8427.
Kozlov, A. P. (2008). Med. Hypotheses. 1996. V. 46. P. 81-84.28. Arendt D. // Nat. Rev. Genet. 2008. V. 9. P. 868-882.

Kumar, S., Verma, A. K., Mondal, S. K., Gupta, M., Patil, A. K., \& Lal Jangir, B. (2012). Effect of live Saccharomyces cerevisiae feeding on serum biochemistry in early weaned cross bred piglets. Veterinary World, 5(11).

Levakhin, V. I. (2013). And other Probiotics in animal husbandry // Bulletin of meat cattle breeding. - 2013. - T. 5, No. 21. - S. 87-95.

Lim, S. M., \& Im, D. S. (2009). Screening and Characterization of Pro Biotic Lactic Acid Bacteria Isolated from Korean Fermented Foods. Journal of Microbiology and Biotechnology, 19(2), 178-186. https://www.koreascience.or.kr/article/JAKO200909 651053785.page

Shevchenko, Y. L. (2002). Microbiology. 2002. No 6. P. 2-5.

Valentine, J. W., Collins, A. G., Meyer, C. P. (1987). Paleobiology. 1994. V. 20. P. 131-142.26. Kozlov A.P.//Theoretical and Mathematical Aspects of Morphogenesis. Moscow: Nauka, 1987. P. 136-140.

Wagner, G. P. (2014). Homology, genes and evolutionary innovation. princeton university press. doi.org/10.1515/9781400851461 